\title{
The Impact of Job Commitment on the Relationship between Organizational Culture and Sustainable Development
}

\author{
Mai El-Sayed, Mohamed Wahba, Mohamed A. Ragheb, Alaa Elgharabawy \\ The Arab Academy for Science and Technology \& Maritime Transport, Alexandria, Egypt \\ Email: Mwahba@aast.edu,raghebmm@aast.edu, agharbawy@comm.alexu.edu.eg
}

How to cite this paper: El-Sayed, M., Wahba, M., Ragheb, M.A. and Elgharabawy, A. (2021) The Impact of Job Commitment on the Relationship between Organizational Culture and Sustainable Development. Open Access Library Journal, 8: e6998.

https://doi.org/10.4236/oalib.1106998

Received: November 15, 2020

Accepted: February 22, 2021

Published: February 25, 2021

Copyright $\odot 2021$ by author(s) and Open Access Library Inc.

This work is licensed under the Creative Commons Attribution International License (CC BY 4.0).

http://creativecommons.org/licenses/by/4.0/

\begin{abstract}
This research investigates the impact of organizational culture and job commitment on sustainable development, which will help improve its performance through job commitment. A structured questionnaire was developed and administrated to a sample of Citadel Capital employees. The data analysis phase comes after the researcher completes the data collection phase. Looking at the results of analyzing the role of organizational culture and sustainable development, it has shown that there is a significant relationship between them. Based on the results of analyzing the role of organizational culture and job commitment, it has shown that there is a significant relationship between them. Based on the results of analyzing the role of job commitment and sustainable development, it has shown that there is a significant relationship between them.
\end{abstract}

\section{Subject Areas \\ Human Resource Management}

\section{Keywords}

Organizational Culture, Job Commitment, Sustainable Development

\section{Introduction}

Business organizations always strive to achieve administrative efficiency and effectiveness in order to achieve the goals, and advanced business organizations pay great attention to the development and improvement of performance by adopting modern management methods. Among the recent trends of these organizations is the extreme interest in the organizational culture of the organiza- 
tion, where the organizational culture is considered as one of the most important features of modern management. It is considered an important element in the formation of business organizations as it plays a vital role in embodying and developing modern managerial thought, and it is considered an important element in influencing organizational behavior. Each organization has its own culture. Organizational Culture plays a major role at all levels within the administrative organization as it contributes to creating the appropriate organizational climate that helps to improve and develop performance in an appropriate and effective manner. The importance of organizational culture has increased because it affects the behavior of workers in the workplace, as this would increase job commitment towards the organization.

In addition, to acquire new members, the organizational culture has to achieve belonging and ensuring survival in the organization. The importance of organizational culture has increased because it affects the behavior of workers in the workplace, as this would increase job commitment towards the organization. In order to achieve sustainable development, even at the institutional level, it forces the institution to adopt such types of modern management methods [1].

The term sustainable development is not limited to economic development only, but goes beyond it to refer to a wide range of multifaceted issues for managing the economy, environment and society. As sustainable development is development with three dimensions, economic, social and environmental meaning that sustainable development is a development that does not focus on the environmental aspect only, but rather includes also the economic and social aspects, and each of these dimensions consists of a group of elements. Sustainable economic development is the system that is able to produce goods and services continuously.

The task of management and managers, as they do not resort to strict procedures to confirm and apply the required behavior within the organization, to achieve creativity and competitive excellence for the organization, and to achieve its goals and sustainable development. From here, we conclude that any gap in these practices will affect the performance of the organization and will affect productivity. The main problem of the research can be formulated in the form of the following question:

- What is the impact of the organizational culture on achieving sustainable development through the role of mediator for job commitment on Nile Logistic, a subsidiary of Citadel Holding Company in Egypt?

Besides, the main objective of this research is to test the impact of organizational culture and job commitment on sustainable development, which will help improve its performance through job commitment. This aim will be achieved through some objectives, which are exploring the dimensions of organizational culture and sustainable development, measuring the effect of organizational culture on job commitment, measuring the impact of job commitment on sustainable development, analyzing the impact of organizational culture on sustainable development. 


\section{Literature Review}

The topic of sustainable development in all its dimensions is has a great importance at the global level. In the recent period, an increasing international concern has been observed towards the need to achieve sustainable development in order to reach a sustainable future. The term sustainable development is not limited to economic development only, but goes beyond it to refer to a wide range of multifaceted issues for managing the economy, the environment and society. Just as sustainable development is development in three dimensions, economic, social and environmental, meaning that sustainable development is a development that does not focus on the environmental aspect only. Rather includes also, the economic and social aspects, and each of these dimensions consists of a group of elements. Sustainable economic development is the system that is able to produce goods and services continuously. To define sustainable development as the necessity for achieving development in a way that satisfies the developmental and environmental needs of present and future generations as well, and this concept emerged as a development philosophy. New based on the principle of sustainability, the goal of which is to eliminate the current production and consumption patterns whether in developed or developing countries. In addition, to replace them with production and consumption patterns that preserve the environment and its resources without depletion and without wasting and to preserve the rights of the leading generations to benefit from these Resources. Also, as the International Committee for Environment and Development provided a definition for sustainable development as that development that achieves and meets the basic needs of all and provides opportunities for them to achieve their aspirations for a better life. While spreading and encouraging production and consumption patterns within the limits and environmental capabilities that society aspires to achieve in a reasonable way [2]. The countries of the world agreed at the Earth Conference in 1992 to define sustainable development in the third principle approved by the Conference on Environment and Development in Rio de Janeiro, Brazil, in 1992, on the necessity of achieving the right to development so that the development and environmental needs of present and future generations are equally fulfilled.

Sustainable development is also defined as the result of a group interaction in the work of the public and private authorities in society in order to meet the basic and health needs of the human being. It organizes economic development for its benefit and the pursuit of social harmony in society, regardless of the cultural, linguistic and religious differences of people, without mortgaging the future of future generations to meet their needs [2].

As we mentioned before, sustainable development is development with three dimensions, economic, social and environmental, meaning that sustainable development is development that does not focus on the environmental aspect only, but also includes economic and social aspects, and each of these dimensions consists of a group of elements. These three elements form the basic pillars of 
sustainable development. Through this research, the researcher will try to address the concept of sustainable development, explaining its dimensions and the elements of both economic sustainability, environmental sustainability and social sustainability. Moreover, how the impact and importance of both organizational culture and job commitment on sustainable development.

The idea of organizational culture has attracted the interest of researchers and scholars in the organization's behavior, leadership behavior, management behavior, managers, workers and dealers, as it is one of the components of the organization's external and internal environment. The idea is based on raising the attention of specialists. Thinking about the management style of the organization's culture, which embodies the essence of its role in the life of the organization and its human resources, which leads to achieving Superiority, internal and external, and gives it the characteristic of continuity, vitality and renewal. Where the organizational culture of the organization is the identity that distinguishes it from other organizations because it reflects its personality and social structure, and then each organization has its own culture because it represents the values, habits, attitudes of employees, their managers, their behavior patterns and their ways of thinking. This is shaped by the influence of the type of organization, its organizational climate, and the nature of the society in which it works. Which prompts us to say that each organization is unique in its own culture, but that does not mean that there are no common denominators in the organizations' culture. Through this topic, the researcher will try to address the concept of organizational culture, which has become a major indicator of the success of economic and administrative institutions and organizations, with some kind of explanation and analysis for that. As well as its elements, types, importance, factors that help its survival, dimensions of organizational culture and its impact on both career commitment and sustainable development.

Commitment is a manifestation of human behavior that includes all aspects of mental, motor, emotional and social activity performed by individuals. Job commitment has an effective role within organizations, institutions and companies because it increases the employees' attachment to their work and makes them make a great effort to achieve the goals of the company, institution or organization and work on their development, increase their production and achieve their competitive advantage. Job commitment also reduces negative behavior such as neglect, default at work, absence, leaving work and other negative behaviors. Job commitment also helps raise the level of employee satisfaction, which reflects the low turnover and absence of employees. It also increases the level of belonging to the institution, increases productivity and reduces the productive cost of the institution. It also increases the efficiency and effectiveness of the performance of the employees of the institution, company or organization.

The researcher will explain organizational culture and job commitment and their impact on sustainable development, as sustainable development is consi- 
dered a dependent variable, and job commitment plays a mediating role in the relationship between organizational culture and its impact on sustainable development. Previous studies dealing with these relationships are presented and clarified and the theoretical framework of concepts is presented explaining the methodological aspects of these studies. The researcher will address previous studies related to this research through eight sections as the first section includes the introduction to this chapter, and the second section deals with the definition of organizational culture, while the section deals, the third is the definition of job commitment. As for the fourth section, it includes an introduction to the concept of sustainable development. As for the fifth section, the researcher will discuss the relationship between organizational culture and sustainable development, and the researchers will present the relationship between organizational culture and job commitment in the sixth section, as for the seventh section. It includes the relationship between career commitment and sustainable development, and at the end, the researcher will arrive at the results of previous studies through the eighth section, which is represented in the conclusion.

Many researchers unanimously agree on the importance of organizational culture and its effective role in shaping the individual's values, motives and trends. Each society has its own culture, and each organization has its own organizational culture, as organizational culture is one of the most prominent modern approaches to managing change and development, and it affects the effectiveness and efficiency of the organization. Culture performs several functions for organizations as it has a negative or positive impact on its outputs on feeling Workers with satisfaction, belonging, loyalty and commitment as they affect the performance behavior of individuals and the cohesion of the social structure of the organization.

Organizational culture was defined according to [3] as the basic values adopted by the organization, the philosophy that governs its policy towards employees, the way in which tasks are accomplished, and the assumptions and beliefs that are shared by the members of the organization. Organizational culture is a set of principles that organizations invented and developed while solving their problems of external adaptation and internal integration, and they have proven effective and taught to new members. Organizational culture is also defined as a set of values and behavioral patterns that individuals and universities share within the organization [4].

Organizational Culture is also defined as a set of assumptions, beliefs, values, rules and norms shared by the members of the organization. It was found that the organizational culture consists of organizational elements, whereby the organization's culture is formed from a set of values, ideas and principles that crystallize among individuals. Culture is what gives the institution a certain characteristic, culture is a factor for cohesion and differentiation. In addition, the organizational culture consists of a set of social characteristics, symbols and values that individuals share and achieve cohesion. These features consist of the 
founders, the institution's history, profession and values. There are two types of organizational culture, namely: the strong culture and the weak culture, and its types are determined based on its components and results. As a strong organizational culture is accepted and trusted by all members of the organization who share a homogeneous set of values, beliefs, traditions, norms and assumptions that govern their behaviors and attitudes within the organization. As for the weak organizational culture, it is not trusted and accepted by most of the organization members. As there is difficulty in agreeing on its objectives among the members of the organization.

Several factors affect the organizational culture (size of the organization, management functions, technology, socialization, senior management statements, and organizational age). As the size of the organization as the larger the size of the organization the more difficult it is to form a strong organizational culture among all members of the organization. The organizational culture is affected by the functions of management, behavior, organizational structure and process, the technology used as it uses modern techniques, the more it strengthens the organizational culture of the organization, the social upbringing. where the more socialization of workers under commitment, the more it helps in forming a strong organizational culture. The formation and change of the organizational culture, and the organizational age, as the more the organization has a lifetime history, the greater its pinch in the formation of a strong organizational culture.

There are also mechanisms for preserving the organizational culture, as there are several factors that play an important role in preserving the organizational culture, namely: higher management, staff selection, and social mixing). With regard to the top management, it works to preserve its culture through its commitment and preservation of its policy by how to deal with employees and the management policy about implementing the organization's rules. Those with skills and abilities so that there is no difference between the values of the enterprise and the values of the workers. As for social contact, where the organization's management must introduce new workers to the culture of the organization and this is in order to avoid differences between workers so as not to affect the organization's performance and effectiveness.

Moreover, Job commitment or job satisfaction referred to an attitude related to general attitudes towards life or life satisfaction also regarding quality of service. It was researched across six major specialties, and these disciplines among doctors saw that the prediction of job satisfaction or job commitment was broad and comprehensive, especially in recent times where researchers suggested that job satisfaction might also be affected by work-related issues and personal characteristics [5]. The work-related dimensions that affect satisfaction depend on certain circumstances at certain times in addition to their dependence on the characteristics of the work environment and the period in which the studies were conducted [6]. There were a number of previous studies conducted on job 
satisfaction and on workers; in general that predicting mental health in terms of workers' health and their satisfaction with the work environment may be an important determinant that affects job satisfaction and commitment [7].

In addition, Sustainable development refers to economic, environmental and social development that meets the needs of the present and does not prevent future generations from meeting their needs. In this context, companies play an important role, however slow progress has been made towards sustainable development, indicating the need for more realistic guidance that will allow companies to act strategically and successfully in a sustainable manner. There are three distinct but integrated dimensions of strategic management as viewed from a sustainability perspective in order to encourage the incorporation of sustainability issues into the activities and strategies of companies. These three dimensions are the strategy process, the content of the strategy, and the strategy context. There are also several proposals related to these dimensions to explore the contributions of corporate sustainability management to creating value for companies, society and nature [8].

Many researches have studied the relationship between Organizational Culture and Sustainable Development. Where the organizational culture and the relationship between organizational culture and business strategies for sustainable development were studied, as sustainable development is always discussed intensively in politics and macroeconomics, but it is rarely discussed at the level of business operations. As the sustainable development and development focus on the primary goals of commercial companies such as economic, environmental and innovation aspects. To achieve the goals of sustainable development, there are three basic organizational variables available: the organizational structure, formal management tools, and organizational culture. Where responsibilities, tasks and procedures for sustainable development are determined by the organizational structure. Formal management systems and tools support line managers. As for the organizational culture, it is the third basic variable for sustainable development management and it is considered the most formal variable from the previous ones [8].

In addition, the importance of the field of communication for sustainable development was studied, as the field of communication is one of the influencing dimensions in the organizational culture, which in turn affects the sustainable development of organizations. Human and environmental sustainability should be fundamental to development and social change activities. To verify the aim of the study, a survey was conducted to collect the targeted data from education, contact and knowledge information. Among the most prominent results that resulted from the study is the field of communication, which is considered one of the most important and influential areas in sustainable development. In addition to the political and economic aspects and their impact on sustainability, there is also a need for sociocultural aspects as they ensure acceptable and integrated levels of sustainability and build the resilience of societies as the resilience 
of societies is considered a priority issue in the field of communications for sustainable development and social change [9].

Many researches have studied the relationship between Organizational Culture and Job Commitment. Where the relationship between internal social responsibility represented in teamwork, communication, reward and appreciation, training and development and their relationship to job commitment were studied. As the job commitment represents the link between the organizational goals and the role of the individual linked to the important goals and values in the organization and thus job commitment can be described as the process. Through which the individual and organizational goals are integrated in the organization where this integration occurs within the organization that creates positive attitudes among individuals towards their organizations and this works. To strengthen the employee's attachment to the organization and the desire to remain in the organization as an active member increases by participating in various organizational behaviors such as increasing citizenship behavior, good job performance, low turnover, low rates of employee delay and absence, as job commitment does not depend only on individual characteristics and characteristics but also on incentives. In addition, the advantages and support provided by the organization to achieve self-goals that in turn affect his career commitment [10].

To verify the aim of the study, a sample consisting of 170 employees of the Jordan cement industry company was selected. Therefore, a questionnaire was distributed to the selected sample to verify the goal of the thesis and explore the relationship between internal social responsibility represented in teamwork, communication, reward, appreciation, training, development, and their relationship to job commitment, and 152 were retrieved. Of the questionnaires, with a response rate of $89 \%, 21$ questionnaires were unusable, as they were either incomplete or did not match the analysis criteria. Among the most prominent results of the study is the existence of a negative relationship between administrative policies and organizational commitment, and there is no statistically significant relationship between institutional innovation and job commitment.

Furthermore, the relationship between organizational culture and job commitment was studied. The data collected from 134 employees from 18 selected SMEs in the city of McCordy. The data were collected using standardized questionnaires to measure corporate culture and organizational commitment. The data were analyzed using Pearson Correlation Factor, regression analysis, independent T-test and ANOVA. The results found that organizational culture has a significant positive impact on employee commitment and concluded that employee participation affects decision-making as well as the organization's ability to adapt to changing circumstances positively on employee commitment to the organization. However, this is not the case for coherent organizations, as is introducing employees to the mission of the organization. Therefore, we conclude that while company culture is important in improving employees' level of commitment to the organization. Therefore, the study recommended that managers 
of small and medium-sized companies in Nigeria should allow as much as the context allows employees to participate actively in decision-making in their organizations, and this would stimulate employee commitment towards achieving the company's goals [11].

Many researches have studied the relationship between Job Commitment and Sustainable Development. Where the effect of Teamwork on three types of obligations, namely, job commitment, continuous commitment and normative commitment, and their impact on increasing employee productivity were investigated and thus the impact on the sustainable development of organizations. One of the results of job participation is job satisfaction, job commitment and job performance for employees, as job participation leads to decision-making and thus improving employee performance, which in turn improves the performance of the organization as a whole and thus increases the sustainable development of these organizations. In order to verify the objective of the study and to prove that Teamwork through job commitment affects the increase in productivity and the increase in sustainable development of companies, the target data for the study were collected through a questionnaire collected from 211 employees in 11 different organizations. One of the findings of the study is to prove the existence of a relationship between Teamwork and job commitment, and this proves that organizations that have a culture of Teamwork among their employees are more committed than organizations that do not involve their employees in making decisions done on Pakistan [12].

\section{Research Methodology}

\subsection{Research Approach}

Research methodology is a systematic process that helps the researcher to conduct the research systematically and it is the process of collecting different ideas, theories and concepts. Therefore, that the researcher can link them to a specific field in the research as the research methodology is a system that contains different methods that the researcher can follow to conduct the research in order to achieve goals and objectives search [13].

The main purpose of this study is to examine the relationship between the organizational culture (Teamwork, Communication, Reward and Recognition and Training and Development) and job commitment on sustainable development (Economic Sustainability, Environmental Sustainability and Social Sustainability). Therefore, the researcher depended on positivism philosophy using deductive approach. The research built upon the quantitative approach by collecting cross-sectional data (primary data) collected through questionnaires.

The key to the methodology of positivism philosophy is the experiment that allows them to test cause-and-effect relationships through manipulation and observation. Some theorists believe that the goal of research is to describe phenomena that one can directly observe and measure objectively. For them, knowing anything behind this, such as emotions, feelings and thoughts, is impossible. 
Because here the descriptive philosophy is compatible with the nature of the subject of study, which is the study of the relationship between organizational culture and sustainable development through the mediating role-played by job commitment in this relationship. Therefore, descriptive analytical philosophy was used through the office study in order to gain familiarity with all concepts of organizational culture, sustainable development and job commitment. Through a desk survey and the researcher's reliance on collecting primary and secondary data by examining the various references related to the topic from previous studies, scientific articles, books, research and accurate scientific messages as well, the applied study was used by collecting its data and then interpreting it based on the distribution of the questionnaire forms as a tool. Main, and work on analyzing that data and showing the effect of the variables that have been selected to reach results that are useful in the decision-making process.

In this study, the researcher relies on the inductive approach, as it is the prevailing research method in the natural sciences, where laws provide the basis for interpretation, allow for the anticipation of phenomena, predict their occurrence, and thus allow their monitoring.

This research depends on the quantitative approach, whereby a questionnaire is distributed to know the impact of organizational culture dimensions on sustainable development through the mediating role of job commitment.

\subsection{Variables and Measurements}

The variables used in this study can be categorized into two main types, which are; the dependent and independent variables

\subsubsection{Dependent Variable}

Organizational culture (Teamwork, Communication, Reward and Recognition and Training and Development)

\subsubsection{Independent Variable}

Sustainable development (Economic Sustainability, Environmental Sustainability and Social Sustainability).

\subsubsection{Mediator Variable}

Job Commitment.

- The current paper conceptual framework is illustrated in Figure 1.

\section{Data Analysis and Findings}

This section will introduce the empirical study with the main findings and results after running the data analysis. This section deals with analyzing the questionnaire under study in addition to identifying the statistical methods that the researcher relied on in analyzing the applied study data, which includes descriptive statistical analysis of the answers of the research sample and testing the study hypotheses. This section introduces the applied study of the model under study. The researcher first presents the descriptive analysis of the data and the 


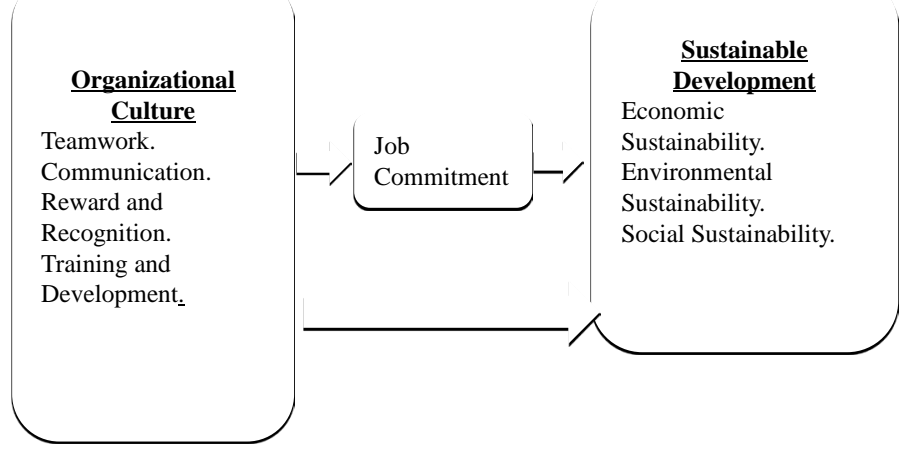

Figure 1. Relationship Diagram between independent variables and dependent variables. Source: Shemelis, 2017, Atmaca et al., 2019.

structural equation model under study. These tests are laboratory tests that require the normal distribution of the data under study, which the researcher has tested, as shown below. When performing the structural validity test of the sample, it was found that all the values of the average interpreted variance are greater than $50 \%$. The values of the load coefficients are greater than 0.4 , and that the Cronbach alpha coefficients are greater than 0.7 , which are all acceptable values for testing the measurement stability of each of the study variables.

\subsection{Descriptive Analysis}

The descriptive statistics is a tool in which it explains and gives a distinct understanding of the features of certain data set, by giving short summaries about samples and how to measure the data. Table 1 illustrates the descriptive analysis for the research variables using the Mean, and Standard Deviation for the research variables.

The variables were computed as the average or the round average of the valid and reliable statements considered for each construct. Then the mean and standard deviation were computed for each variable as following: The mean value of Teamwork is found to be 3.8165 with a standard deviation of 0.66319 . In addition, the mean value of Communication is found to be 3.8991 with a standard deviation of 0.56642. In addition, the mean value of Training and Development is found to be 3.8555 with a standard deviation of 0.62495 . In addition, the mean value of Reward and Recognition is found to be 3.9977 with a standard deviation of 0.69646. In addition, the mean value of Job Commitment is found to be 4.0482 with a standard deviation of 0.69147 . In addition, the mean value of Economic Sustainability is found to be 3.9472 with a standard deviation of 0.60227. In addition, the mean value of Social Sustainability is found to be 4.5252 with a standard deviation of 0.59253 . In addition, the mean value of Environmental Sustainability is found to be 4.2523 with a standard deviation of 0.56781 .

\subsection{Normality Testing for the Research Variables}

Normality is one of the assumptions that have to be verified to determine if a 
data set is normal. In order to check the normality for the data. According to Table 2, the test of normality, where it could be shown that some of the Skewness and kurtosis values are in the acceptance level of \pm 1 , which means that the data under study are approximately normal. Consequently, Pooled Regression used to describe the relationships between the research variables by using GLS Technique.

\subsection{Multiple Regression}

\section{The first Hypothesis:}

- The first Sub-Hypothesis:

The multiple regression model shows the organizational culture, including (teamwork, communication, training and development, reward and appreciation) and their impact on the dependent variable economic sustainability. The researcher found that there is a positive significant impact for each of the teamwork, communication, training and development, reward and appreciation on sustainability Economic, as the significance level values are less than 0.05 and the regression coefficient values are $0.124,0.281,0.182$, and 0.152 . Moreover, its $\mathrm{R}$ Square value is 0.304 , which means that $30.4 \%$ of economic sustainability can be explained by organizational culture.

Table 1. Descriptive analysis.

\begin{tabular}{cccc}
\hline & N & Mean & Std. Deviation \\
\hline Teamwork & 436 & 3.8165 & 0.66319 \\
Communication & 436 & 3.8991 & 0.56642 \\
Training and Development & 436 & 3.8555 & 0.62495 \\
Reward and Recognition & 436 & 3.9977 & 0.69646 \\
Job Commitment & 436 & 4.0482 & 0.69147 \\
Economic Sustainability & 436 & 3.9472 & 0.60227 \\
Social Sustainability & 436 & 4.5252 & 0.59253 \\
Environmental Sustainability & 436 & 4.2523 & 0.56781 \\
\hline
\end{tabular}

Table 2. Normality testing for the research variables.

\begin{tabular}{cccccc}
\hline \multirow{2}{*}{ Research Variables } & N & \multicolumn{2}{c}{ Kurtosis } & \multicolumn{2}{c}{ Skewness } \\
\cline { 2 - 6 } & Statistic & Std. Error & Statistic & Std. Error & Statistic \\
\hline Teamwork & 436 & 0.233 & -0.763 & 0.117 & 0.222 \\
Communication & 436 & 0.233 & 0.034 & 0.117 & -0.017 \\
Training and Development & 436 & 0.233 & -0.508 & 0.117 & 0.113 \\
Reward and Recognition & 436 & 0.233 & -0.931 & 0.117 & 0.003 \\
Job Commitment & 436 & 0.233 & -0.902 & 0.117 & -0.064 \\
Economic Sustainability & 436 & 0.233 & -0.243 & 0.117 & 0.022 \\
Social Sustainability & 436 & 0.233 & -0.294 & 0.117 & -0.831 \\
Environmental Sustainability & 436 & 0.233 & -0.423 & 0.117 & -0.040 \\
\hline
\end{tabular}


Based on the data in Table 3, the independent variables are gradient in importance to the dependent variable, where "communication" is the most important variable for economic sustainability, as the corresponding Standardized Beta is 0.264 . It is followed by training and development, where the corresponding Beta value is 0.189 . Then comes the reward and appreciation in the third place in terms of importance in terms of economic sustainability, as the corresponding Beta Standardized value is equal to 0.176 and in the last place collective action comes as the least important variable for economic sustainability, as the corresponding Standardized Beta is equal to 0.137 .

Based on the previous results, it can be seen that the first sub-hypothesis of the first hypothesis "There is a statistically significant relationship between organizational culture and economic sustainability" is fully acceptable.

- The Second Sub-Hypothesis:

The multiple regression model shows the organizational culture, including (teamwork, communication, training and development, reward and appreciation) and their impact on the dependent variable, environmental sustainability. The researcher found that there is a positive significant impact for each of the teamwork, communication, training and development, reward and appreciation on sustainability Environmental where the significance level values are less than 0.05 and the regression coefficient values are $0.162,0.248,0.115$, and 0.084 . Moreover, its R square value is 0.226 , which means that $22.6 \%$ of environmental sustainability can be explained by organizational culture.

Based on the data in Table 4, the independent variables are of significance relative to the dependent variable, as we find that communication is the most important variable for environmental sustainability, as the corresponding Standardized Beta value is 0.248. Teamwork comes next in importance, as the corresponding Standardized Beta value is 0.190, then training and development comes in third place in importance, as the corresponding Standardized Beta is 0.126. Reward and recognition are the least important variable on environmental sustainability, as the corresponding Standardized Beta is 0.103 .

Table 3. Regression analysis of the impact of organizational culture on economic sustainability.

\begin{tabular}{|c|c|c|c|c|c|c|}
\hline \multirow[t]{2}{*}{ Model } & \multicolumn{2}{|c|}{$\begin{array}{l}\text { Unstandardized } \\
\text { Coefficients }\end{array}$} & \multirow{2}{*}{$\begin{array}{c}\text { Standardized } \\
\text { Coefficients }\end{array}$} & \multirow[t]{2}{*}{$\mathrm{T}$} & \multirow{2}{*}{ Sig. } & \multirow[t]{2}{*}{ R Square } \\
\hline & B & Std. Error & & & & \\
\hline (Constant) & 1.066 & 0.214 & & 4.976 & 0.000 & \\
\hline Teamwork & 0.124 & 0.041 & 0.137 & 3.034 & 0.003 & \\
\hline Communication & 0.281 & 0.046 & 0.264 & 6.075 & 0.000 & 0.304 \\
\hline training and development & 0.182 & 0.049 & 0.189 & 3.749 & 0.000 & \\
\hline reward and appreciation & 0.152 & 0.041 & 0.176 & 3.700 & 0.000 & \\
\hline
\end{tabular}

a. Dependent Variable: economic sustainability. So the regression equation can be written as follows: Economic Sustainability $=1.066+0.124$ Teamwork +0.281 Communication +0.182 Training and Development +0.152 Reward and Recognition. 
Table 4. Regression analysis of the impact of organizational culture on environmental sustainability.

\begin{tabular}{cccccccc}
\hline \multirow{2}{*}{ Model } & \multicolumn{2}{c}{$\begin{array}{c}\text { Unstandardized } \\
\text { Coefficients }\end{array}$} & $\begin{array}{c}\text { Standardized } \\
\text { Coefficients }\end{array}$ & t & Sig. & R Square \\
\cline { 2 - 5 } & B & Std. Error & Beta & & & \\
\hline (Constant) & 1.885 & 0.213 & & 8.850 & 0.000 & \\
Teamwork & 0.162 & 0.041 & 0.190 & 3.985 & 0.000 & \\
communication & 0.248 & 0.046 & 0.248 & 5.397 & 0.000 & 0.226 \\
training and development & 0.115 & 0.048 & 0.126 & 2.373 & 0.018 & \\
Reward and recognition & 0.084 & 0.041 & 0.103 & 2.067 & 0.039 & \\
\hline
\end{tabular}

a. Dependent Variable: environmental sustainability. So the regression equation can be written as follows: Environmental Sustainability $=1.885+0.162$ Teamwork +0.248 Communication +0.115 Training and Development +0.084 Reward and Recognition.

Based on the previous results, it can be seen that the second sub-hypothesis of the first hypothesis "There is a statistically significant relationship between organizational culture and environmental sustainability" is fully acceptable.

- The Third Sub-Hypothesis:

The multiple regression model shows the organizational culture, including (teamwork, communication, training and development, reward and appreciation) and their impact on the dependent variable, which is social sustainability. Social where the significance level values are less than 0.05 and the regression coefficient values are $0.208,0.119,0.109$, and 0.104 . Moreover, its R Square value is 0.179 , which means that $17.9 \%$ of social sustainability can be explained by organizational culture.

Based on the data in Table 5, the independent variables are ranked in importance relative to the dependent variable, as teamwork is the most important variable for social sustainability, as the corresponding Standardized Beta value is equal to 0.233 . And is followed by importance, reward and appreciation, as the Standardized value The corresponding Beta is 0.122 , then comes the training and development, as the corresponding Standardized Beta is 0.115, and in the last place communication comes as the least important variable for social sustainability, as the corresponding Standardized Beta is 0.114 .

Based on the previous results, it can be seen that the third sub-hypothesis of the first hypothesis "There is a statistically significant relationship between organizational culture and social sustainability" is fully acceptable.

Based on these results, the first hypothesis "there is a statistically significant relationship between organizational culture and sustainable development" is fully acceptable.

\section{The second Hypothesis:}

- The multiple regression model shows the organizational culture, including (teamwork, communication, training and development, reward and appreciation) and their impact on the dependent variable, which is job commitment, and the researcher found that there is a positive moral effect for both team- 
work, communication, training and development, reward and appreciation on job commitment. Where the significance level values are less than 0.05 and the regression coefficient values are $0.291,0.351,0.184$ and 0.124 . Moreover, its R Square value is 0.373 , which means that $37.3 \%$ of job commitment can be explained by job commitment.

Based on the data in Table 6, the independent variables are ranked in importance relative to the dependent variable as communication is the most important variable for job commitment, as the corresponding Standardized Beta is 0.288. Teamwork comes next in importance, as the corresponding Standardized Beta value is 0.279 , then comes training and development, as the corresponding Standardized Beta is 0.166, and in the last place the reward and appreciation comes as the least important variable on job commitment, as the corresponding Standardized Beta is 0.124 .

Based on the previous results, it can be seen that the second hypothesis "there is a statistically significant relationship between organizational culture and social sustainability" is fully acceptable.

Table 5. Regression analysis of the impact of organizational culture on social sustainability.

\begin{tabular}{cccccccc}
\hline \multirow{2}{*}{ Model } & \multicolumn{2}{c}{$\begin{array}{c}\text { Unstandardized } \\
\text { Coefficients }\end{array}$} & $\begin{array}{c}\text { Standardized } \\
\text { Coefficients }\end{array}$ & T & Sig. & R Square \\
\cline { 2 - 5 } & B & Std. Error & Beta & & & \\
\hline $\begin{array}{c}\text { (Constant) } \\
\text { teamwork }\end{array}$ & 2.430 & 0.229 & & 10.621 & 0.000 & \\
communication & 0.208 & 0.044 & 0.233 & 4.764 & 0.000 & \\
training and development & 0.119 & 0.049 & 0.114 & 2.413 & 0.016 & 0.179 \\
reward and appreciation & 0.104 & 0.052 & 0.115 & 2.089 & 0.037 & \\
\hline
\end{tabular}

a. Dependent Variable: Social Sustainability. So the regression equation can be written as follows: Social Sustainability $=2.430+0.208$ Teamwork +0.119 Communication +0.109 Training and Development +0.104 Reward and Recognition.

Table 6. Regression analysis of the effect of organizational culture on job commitment.

\begin{tabular}{|c|c|c|c|c|c|c|}
\hline \multirow[t]{2}{*}{ Model } & \multicolumn{2}{|c|}{$\begin{array}{l}\text { Unstandardized } \\
\text { Coefficients }\end{array}$} & \multirow{2}{*}{$\begin{array}{c}\begin{array}{c}\text { Standardized } \\
\text { Coefficients }\end{array} \\
\text { Beta }\end{array}$} & \multirow[t]{2}{*}{$\mathrm{T}$} & \multirow[t]{2}{*}{ Sig. } & \multirow[t]{2}{*}{ R Square } \\
\hline & B & Std. Error & & & & \\
\hline (Constant) & 0.366 & 0.233 & & 1.569 & 0.117 & \\
\hline Teamwork & 0.291 & 0.045 & 0.279 & 6.507 & 0.000 & \\
\hline Communication & 0.351 & 0.050 & 0.288 & 6.966 & 0.000 & 0.373 \\
\hline training and development & 0.184 & 0.053 & 0.166 & 3.470 & 0.001 & \\
\hline reward and appreciation & 0.124 & 0.045 & 0.124 & 2.761 & 0.006 & \\
\hline
\end{tabular}

a. Dependent Variable: Job Commitment. So the regression equation can be written as follows: Job commitment $=0.366+0.291$ teamwork +0.351 communication +0.184 training and development +0.124 reward and recognition. 


\section{The Third Hypothesis:}

\section{- The First Sub-Hypothesis:}

The regression model shows job commitment and economic sustainability. The researcher found that there is a positive significant effect on job commitment and economic sustainability, as the significance level value is less than 0.05 and the regression coefficient value is 0.385 . Moreover, its $\mathrm{R}$ Square value is 0.196 , which means that $19.6 \%$ of economic sustainability can be explained by job commitment (Table 7).

Based on the previous results, it can be seen that the first sub-hypothesis of the third hypothesis "there is a statistically significant relationship between job commitment and economic sustainability" is fully acceptable.

- The Second Sub-Hypothesis:

The regression model shows job commitment and environmental sustainability. The researcher found that there is a positive significant effect on job commitment and environmental sustainability, as the significance level value is less than 0.05 and the regression coefficient value is 0.264 . Moreover, its R Square value is 0.095 , which means that $9.5 \%$ of environmental sustainability can be explained by job commitment (Table 8).

Based on the previous results, it can be seen that the second sub-hypothesis of the third hypothesis "there is a statistically significant relationship between job commitment and environmental sustainability" is fully acceptable.

- The Third sub-Hypothesis:

The regression model shows job commitment and social sustainability. The researcher found that there is a positive significant effect on job commitment and social sustainability as the significance level value is less than 0.05 and the regression coefficient value is 0.244 (Table 9). Moreover, its R Square value is 0.088 , which means that $8.8 \%$ of social sustainability can be explained by job commitment.

Based on the previous results, it can be seen that the third sub-hypothesis of the third hypothesis "There is a statistically significant relationship between job commitment and social sustainability" is fully acceptable.

Based on these results, the third hypothesis "there is a statistically significant relationship between job commitment and sustainable development" is fully acceptable. That is why job commitment can play the mediating role between organizational culture and sustainable development.

Table 7. Regression analysis of the impact of job commitment and economic sustainability.

\begin{tabular}{cccccccc}
\hline \multirow{2}{*}{ Model } & \multicolumn{2}{c}{$\begin{array}{c}\text { Unstandardized } \\
\text { Coefficients }\end{array}$} & $\begin{array}{c}\text { Standardized } \\
\text { Coefficients }\end{array}$ & T & Sig. & R Square \\
\cline { 2 - 4 } & B & Std. Error & Beta & & & \\
\hline (Constant) & 2.388 & 0.154 & & 15.507 & 0.000 & 0.196 \\
Job Commitment & 0.385 & 0.037 & 0.442 & 10.271 & 0.000 & \\
\hline
\end{tabular}

a. Dependent Variable: Economic Sustainability. So the regression equation can be written as follows: Economic sustainability $=2.388+0.385 \mathrm{Job}$ commitment. 
Table 8. Regression analysis of the impact of job commitment and environmental sustainability.

\begin{tabular}{cccccccc}
\hline \multirow{2}{*}{ Model } & \multicolumn{2}{c}{$\begin{array}{c}\text { Unstandardized } \\
\text { Coefficients }\end{array}$} & $\begin{array}{c}\text { Standardized } \\
\text { Coefficients }\end{array}$ & $\mathbf{t}$ & Sig. & R Square \\
\cline { 2 - 5 } & B & Std. Error & Beta & & & \\
\hline (Constant) & 3.455 & 0.161 & & 21.504 & 0.000 & 0.095 \\
Job Commitment & 0.264 & 0.039 & 0.308 & 6.755 & 0.000 & \\
\hline
\end{tabular}

a. Dependent Variable: Environmental Sustainability. So the regression equation can be written as follows: Environmental sustainability $=3.455+0.264 \mathrm{Job}$ commitment.

Table 9. Regression analysis of the impact of job commitment and Social sustainability.

\begin{tabular}{cccccccc}
\hline \multirow{2}{*}{ Model } & \multicolumn{2}{c}{$\begin{array}{c}\text { Unstandardized } \\
\text { Coefficients }\end{array}$} & $\begin{array}{c}\text { Standardized } \\
\text { Coefficients }\end{array}$ & T & Sig. & R Square \\
\cline { 2 - 4 } & B & Std. Error & Beta & & & \\
\hline (Constant) & 3.265 & 0.155 & & 21.125 & 0.000 & 0.088 \\
Job Commitment & 0.244 & 0.038 & 0.297 & 6.476 & 0.000 & \\
\hline
\end{tabular}

a. Dependent Variable: Social Sustainability. So the regression equation can be written as follows: Social sustainability $=3.265+0.244 \mathrm{Job}$ commitment.

\section{The Fourth Hypothesis:}

This hypothesis tests the mediation of job commitment in the relationship between organizational culture and sustainability. Table 10 presents the results of the multiple regression model test of organizational culture on economic sustainability. It has been found that there is a significant impact of organizational culture on economic sustainability. In addition, the results of the organizational culture multiple regression model test on job commitment were shown. It was found that there is a significant effect of organizational culture on job commitment. There is a significant effect of organizational commitment on economic sustainability as its significance level value is less than 0.05 . Therefore, job commitment completely mediates the relationship between teamwork and economic sustainability, while partly mediating the relationship between communication, training and development, reward and appreciation, and economic sustainability.

Based on the data in Table 9, the independent variables are of importance relative to the dependent variable, as we find that communication is the most important variable for economic sustainability, as the corresponding Standardized Beta is 0.213. Next in importance is job commitment, as the corresponding Standardized Beta is 0.180 . Then Training and Development comes in third, with the corresponding Standardized Beta of 0.159. It is followed by the reward and recognition fourth in importance for economic sustainability, with the corresponding Beta value of 0.153 . Finally, Teamwork is the least important variable for economic sustainability, with the corresponding Standardized Beta of 0.087.

Results of analyzing the role of job commitment mediation between organiza- 
tional culture and environmental sustainability, and it was found that there is no significant effect of organizational commitment on environmental sustainability as its significance level values are greater than 0.05. Based on the data in Table 11 , the independent variables are of importance relative to the dependent variable, as we find that communication is the most important variable for environmental sustainability, as the corresponding Standardized Beta is 0.244. Teamwork comes next in importance, as the corresponding Standardized Beta is 0.186 , then comes training and development, as the corresponding Standardized Beta is 0.124 , and after it comes the reward and appreciation, as the corresponding Standardized Beta equals 0.102. Job commitment comes in last place as the least important variable for environmental sustainability, with the corresponding Standardized Beta of 0.012 .

Table 10. Analyzing the role of job compliance mediation between organizational culture and economic sustainability.

\begin{tabular}{|c|c|c|c|c|c|}
\hline \multirow[t]{2}{*}{ Model } & \multicolumn{2}{|c|}{$\begin{array}{l}\text { Unstandardized } \\
\text { Coefficients }\end{array}$} & \multirow{2}{*}{$\begin{array}{c}\begin{array}{c}\text { Standardized } \\
\text { Coefficients }\end{array} \\
\text { Beta }\end{array}$} & \multirow[t]{2}{*}{$\mathbf{t}$} & \multirow[t]{2}{*}{ Sig. } \\
\hline & B & Std. Error & & & \\
\hline (Constant) & 1.009 & 0.212 & & 4.760 & 0.000 \\
\hline Teamwork & 0.079 & 0.042 & 0.087 & 1.862 & 0.063 \\
\hline communication & 0.226 & 0.048 & 0.213 & 4.698 & 0.000 \\
\hline Training and Development & 0.154 & 0.049 & 0.159 & 3.157 & 0.002 \\
\hline reward and recognition & 0.133 & 0.041 & 0.153 & 3.246 & 0.001 \\
\hline job commitment & 0.156 & 0.044 & 0.180 & 3.586 & 0.000 \\
\hline
\end{tabular}

a. Dependent Variable: economic sustainability. So the regression equation for the mediation role can be written as follows: Economic Sustainability $=1.009+0.079$ Teamwork +0.226 Communication + 0.154 Training and Development +0.133 Reward and Recognition +0.156 Job Commitment.

Table 11. Analyzing the role of job compliance mediation between organizational culture and environmental sustainability.

\begin{tabular}{|c|c|c|c|c|c|}
\hline \multirow[t]{2}{*}{ Model } & \multicolumn{2}{|c|}{$\begin{array}{l}\text { Unstandardized } \\
\text { Coefficients }\end{array}$} & \multirow{2}{*}{$\begin{array}{c}\begin{array}{c}\text { Standardized } \\
\text { Coefficients }\end{array} \\
\text { Beta }\end{array}$} & \multirow[t]{2}{*}{$\mathbf{t}$} & \multirow[t]{2}{*}{ Sig. } \\
\hline & B & Std. Error & & & \\
\hline (Constant) & 1.881 & 0.214 & & 8.798 & 0.000 \\
\hline Teamwork & 0.159 & 0.043 & 0.186 & 3.732 & 0.000 \\
\hline Communication & 0.245 & 0.049 & 0.244 & 5.040 & 0.000 \\
\hline training and development & 0.113 & 0.049 & 0.124 & 2.301 & 0.022 \\
\hline reward and appreciation & 0.083 & 0.041 & 0.102 & 2.017 & 0.044 \\
\hline Job commitment & 0.010 & 0.044 & 0.012 & 0.223 & 0.824 \\
\hline
\end{tabular}

a. Dependent Variable: environmental sustainability. So the regression equation for the mediation role can be written as follows: Environmental Sustainability $=1.881+0.159$ Teamwork +0.245 Communication +0.113 Training and Development +0.083 Reward and Recognition +0.010 Job Commitment. 
Results of analyzing the role of job commitment mediation between organizational culture and social sustainability. It has been shown that there is no significant effect of organizational commitment on social sustainability as its significance level values are greater than 0.05 .

Based on the data in Table 12, the independent variables are ranked in importance relative to the dependent variable, as collective action is the most important variable for social sustainability, as the corresponding Standardized Beta is 0.209 . It is followed by importance, reward and appreciation, as the corresponding Standardized Beta is equal to 0.111 . Then comes training and development as the corresponding Standardized Beta value is 0.100 , and then comes functional commitment as the corresponding Standardized Beta value is 0.089 in the last place communication comes as the least important variable on social sustainability, as the corresponding Standardized Beta value is 0.088 .

\subsection{Structural Equation Modeling}

Table 12 shows the results of analyzing the role of organizational commitment mediation between organizational culture and sustainable development. The researcher found that there is a significant effect of organizational commitment on economic sustainability when the value of the significance level is less than 0.05 , which means that organizational commitment can play the role of a mediator between organizational culture and economic sustainability, while there is no significant effect of organizational commitment on both sustainability. Social, and environmental sustainability as the significance level value is greater than 0.05 . It can be seen that organizational commitment completely mediates the relationship between teamwork, training and development, and economic sustainability, while partly mediating the relationship between communication, reward and appreciation and economic sustainability. The results shown in Table 13 and Figure 2.

Table 12. Analyzing the role of job compliance mediation between organizational culture and social sustainability.

\begin{tabular}{cccccc}
\hline \multirow{2}{*}{ Model } & \multicolumn{2}{c}{$\begin{array}{c}\text { Unstandardized } \\
\text { Coefficients }\end{array}$} & $\begin{array}{c}\text { Standardized } \\
\text { Coefficients }\end{array}$ & $\mathbf{t}$ & Sig. \\
\cline { 2 - 4 } & B & Std. Error & Beta & & \\
\hline (Constant) & 2.402 & .229 & & 10.488 & 0.000 \\
Teamwork & 0.186 & 0.046 & 0.209 & 4.071 & 0.000 \\
Communication & 0.092 & 0.052 & 0.088 & 1.777 & 0.076 \\
training and development & 0.095 & 0.053 & 0.100 & 1.798 & 0.073 \\
reward and appreciation & 0.094 & 0.044 & 0.111 & 2.139 & 0.033 \\
Job commitment & 0.076 & 0.047 & 0.089 & 1.618 & 0.106 \\
\hline
\end{tabular}

a. Dependent Variable: Social Sustainability. So the regression equation for the mediation role can be written as follows: Social Sustainability $=2.402+0.186$ Teamwork +0.092 Communication +0.095 Training and Development +0.094 Reward and Recognition +0.076 Job Commitment. 
Table 13. Structural equation modeling.

\begin{tabular}{|c|c|c|c|c|c|}
\hline & & & Estimates & Indication Level & The Coefficient of determination \\
\hline Teamwork & $--->$ & Job Commitment & 0.251 & $* * *$ & \\
\hline Communication & $--->$ & Job Commitment & 0.294 & $* * *$ & \\
\hline Training and Development & $--->$ & Job Commitment & 0.258 & $* * *$ & 0.455 \\
\hline Reward and Recognition & $--->$ & Job Commitment & 0.206 & 0.001 & \\
\hline Teamwork & $--->$ & Economic Sustainability & 0.059 & 0.109 & \\
\hline Communication & $--->$ & Economic Sustainability & 0.153 & $* * *$ & \\
\hline Training and Development & $--->$ & Economic Sustainability & 0.053 & 0.217 & 0.304 \\
\hline Reward and Recognition & $--->$ & Economic Sustainability & 0.133 & 0.004 & \\
\hline Job Commitment & $--->$ & Economic Sustainability & 0.112 & 0.010 & \\
\hline Teamwork & $--->$ & Social Sustainability & 0.119 & 0.011 & \\
\hline Communication & $--->$ & Social Sustainability & 0.015 & 0.765 & \\
\hline Training and Development & $--->$ & Social Sustainability & 0.075 & 0.163 & 0.141 \\
\hline Reward and Recognition & $--->$ & Social Sustainability & 0.107 & 0.058 & \\
\hline Job Commitment & $--->$ & Social Sustainability & 0.052 & 0.328 & \\
\hline Teamwork & $--->$ & Environmental Sustainability & 0.095 & 0.026 & \\
\hline Communication & $--->$ & Environmental Sustainability & 0.185 & $* * *$ & \\
\hline Training and Development & $-->$ & Environmental Sustainability & 0.135 & 0.008 & 0.274 \\
\hline Reward and Recognition & $--->$ & Environmental Sustainability & 0.060 & 0.240 & \\
\hline Job Commitment & $-->$ & Environmental Sustainability & 0.026 & 0.599 & \\
\hline
\end{tabular}

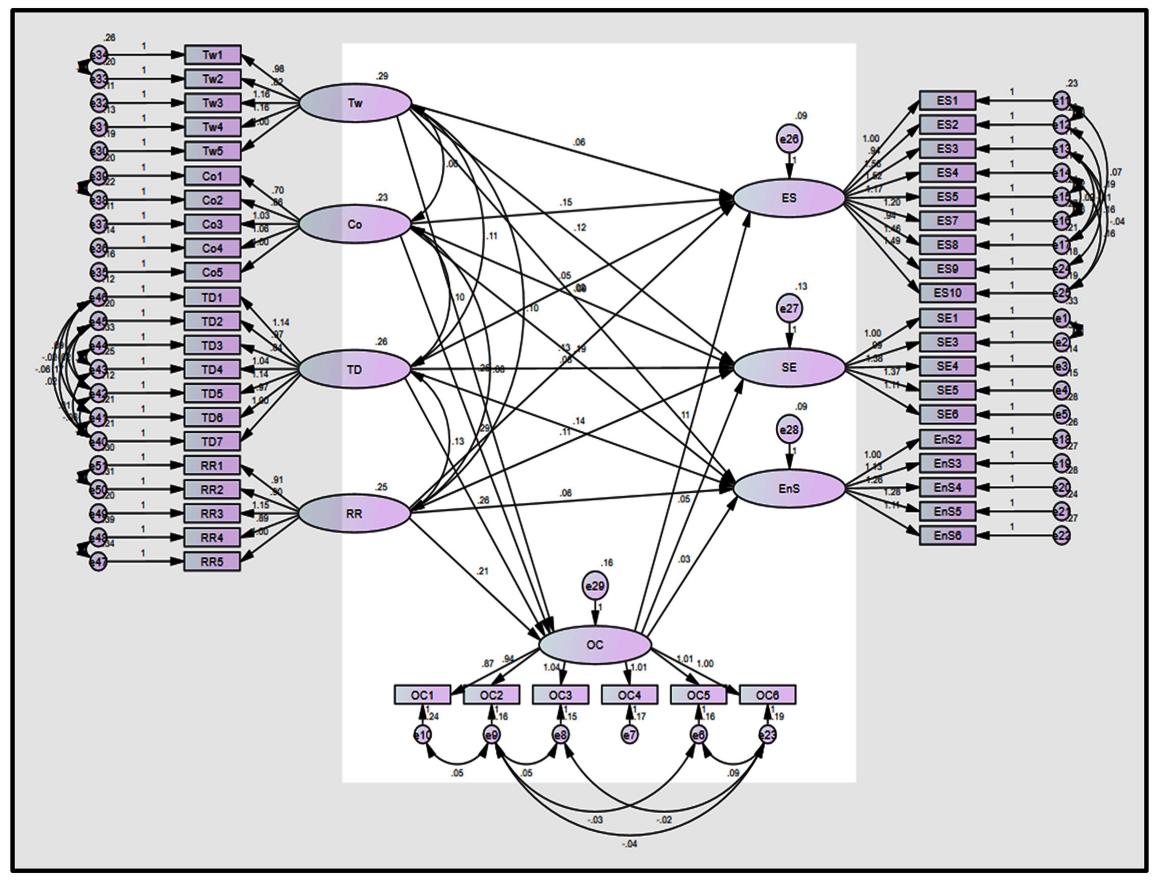

Figure 2. Structural equation modeling. 


\section{Research Recommendations and Limitations}

\subsection{Conclusion}

This section discusses how this research was able to achieve the research objectives. As stated in the first chapter of this research, the research objectives are as follows: The first goal is to measure the impact of organizational culture on sustainable development, the second goal, is to measure the impact of organizational culture and job commitment, and the third goal is to analyze the impact of job commitment on sustainable development. Accordingly, this section discusses each of the aforementioned goals, how it was achieved, to what extent it was achieved, and because of the data collected through the questionnaire that was collected from the study sample consisting of a sample of employees of Citadel Capital.

The first objective: To analyze the impact of organizational culture on sustainable development.

The first main hypothesis: There is a significant relationship between organizational culture and sustainable development.

The first sub-hypothesis: There is a significant relationship between organizational culture and economic sustainability.

By looking at the test of the correlation coefficient between the organizational cultures, which includes (teamwork, communication, training and development, reward and appreciation). Economic sustainability, it was found that there is a positive statistically significant correlation between organizational culture and economic sustainability, as the values of the correlation coefficient are as follows: $0.327,0.409,0.432$ and 0.394 , respectively, with a significance level less than 0.05 .

As for the multiple regression test of organizational culture, which includes: (teamwork, communication, training and development, reward and appreciation) and their impact on the dependent variable, which is economic sustainability. The researcher found that there is a positive significant impact for both teamwork, communication, training and development, reward and appreciation on economic sustainability, where the significance level values are less than 0.05 and the regression coefficient values are $0.124,0.281,0.182$, and 0.152 . Moreover, its R Square value is 0.304 , which means that $30.4 \%$ of economic sustainability can be explained by organizational culture.

Based on the previous results, it can be seen that the first sub-hypothesis of the first hypothesis "There is a significant relationship between organizational culture and economic sustainability" is fully acceptable.

Complementing by looking at the structural equation model for organizational culture, which includes (teamwork, communication, training and development, reward and appreciation) and their impact on the dependent variable, which is economic sustainability, the researcher found that there is a positive moral effect between teamwork, communication, training and development, and rewarding economic sustainability, where the values of the estimates are 0.069 , $0.113,0.107$ and 0.079 , respectively. The significance level values are less than 
0.05. In addition, the value of the coefficient of determination $\mathrm{R}$ Square equals 0.167, which means that the variables: teamwork, communication, training and development, reward and appreciation explain $16.7 \%$ of the change in the dependent variable, economic sustainability.

The second sub-hypothesis: There is a significant relationship between organizational culture and environmental sustainability

Looking at the test of the correlation coefficient between the organizational culture, which includes (teamwork, communication, training and development, reward and appreciation) and environmental sustainability. It was found that there is a positive, statistically significant correlation between organizational culture and environmental sustainability, as the values of the correlation coefficient are as follows: $0.325,0.358,0.349$, and 0.304 , respectively, with a significance level less than 0.05 .

As for the multiple regression test of organizational culture, which includes: (teamwork, communication, training and development, reward and appreciation) and their impact on the dependent variable, which is environmental sustainability, the researcher found that there is a positive significant impact for both teamwork, communication, training and development, reward and appreciation on sustainability. Environmental where the significance level values are less than 0.05 and the regression coefficient values are $0.162,0.248,0.115$, and 0.084 . Moreover, its $\mathrm{R}$ square value is 0.226 , which means that $22.6 \%$ of environmental sustainability can be explained by organizational culture.

Based on the previous results, it can be seen that the second sub-hypothesis of the first hypothesis "There is a statistically significant relationship between organizational culture and environmental sustainability" is fully acceptable.

Complementing by looking at the structural equation model for organizational culture, which includes (teamwork, communication, training and development, reward and appreciation) and their impact on the dependent variable, which is environmental sustainability. The researcher found that there is a positive emotional impact between teamwork, communication, training and development on environmental sustainability. As the values of the estimates are 0.093, 0.195 and 0.167, respectively. The significance level values are less than 0.05. While there is no significant effect of reward and appreciation on environmental sustainability when its significance level value is greater than 0.05 . In addition, the value of the coefficient of determination R Square equals 0.263 , which means that the variables: teamwork, communication, training and development explain $26.3 \%$ of the change in the dependent variable, environmental sustainability.

The third sub-hypothesis: There is a significant relationship between organizational culture and social sustainability

By looking at the test of the correlation coefficient between the organizational culture, which includes (teamwork, communication, training and development, reward and appreciation) and social sustainability. It was found that there is a positive statistically significant correlation between organizational culture and 
environmental sustainability, as the values of the correlation coefficient are as follows: $0.345,0.234,0.317$, and 0.293 , respectively, with a significance level less than 0.05 .

As for the multiple regression test of organizational culture, which includes: (teamwork, communication, training and development, reward and appreciation) and their impact on the dependent variable, which is social sustainability, the researcher found that there is a positive significant impact for both teamwork, communication, training and development, reward and appreciation on sustainability. Social where the significance level values are less than 0.05 and the regression coefficient values are $0.208,0.119,0.109$, and 0.104 . Moreover, its $\mathrm{R}$ Square value is 0.179 , which means that $17.9 \%$ of social sustainability can be explained by organizational culture.

Based on the previous results, it can be seen that the third sub-hypothesis of the first hypothesis "There is a significant relationship between organizational culture and social sustainability" is fully acceptable. Based on these results, the first hypothesis "there is a statistically significant relationship between organizational culture and sustainable development" is fully acceptable.

Complementing by looking at the structural equation model for organizational culture, which includes (teamwork, communication, training and development, reward and appreciation) and their impact on the dependent variable, which is social sustainability. The researcher found that there is a positive emotional impact between teamwork and reward on social sustainability. As the values of the estimates are 0.119 and 0.118 , respectively. The significance level values are less than 0.05 . While there is no significant impact of both communication, training and development on social sustainability when the significance level value is greater than 0.05 . In addition, the value of the coefficient of determination R Square equals 0.131 , which means that the variables: teamwork, reward and appreciation explain $13.1 \%$ of the change in the dependent variable on social sustainability.

The second objective: to measure the effect of organizational culture on job commitment.

The second main hypothesis: There is a significant relationship between organizational culture and job commitment

Looking at testing the correlation coefficient between the organizational culture, which includes (teamwork, communication, training and development, reward and appreciation) and organizational commitment. It was found that there is a positive statistically significant correlation between organizational culture and organizational commitment, as the values of the correlation coefficient are as follows: $0.445,0.435,0.452$ and 0.387 , respectively, with a significance level less than 0.05 .

As for the multiple regression model of organizational culture, which includes: (teamwork, communication, training and development, reward and appreciation) and their impact on the dependent variable, which is organizational 
commitment, the researcher found that there is a positive moral effect for both teamwork, communication, training and development, reward and appreciation for commitment. Regulatory where the significance level values are less than 0.05 and the regression coefficient values are $0.291,0.351,0.184$ and 0.124 . Moreover, the value of R Square is 0.373 , which means that $37.3 \%$ of organizational commitment can be explained by organizational commitment.

Based on the previous results, it can be seen that the second hypothesis "there is a significant relationship between organizational culture and job commitment" is fully acceptable.

Complementing by looking at the structural equation model for organizational culture, which includes (teamwork, communication, training and development, reward and appreciation) and their impact on the dependent variable, which is organizational commitment. The researcher found a positive moral effect between teamwork, communication, training and development, and rewarding organizational commitment. Where the values of the estimates are $0.212,0.305,0.263$ and 0.161 , respectively. The significance level values are less than 0.05 . In addition, the value of the coefficient of determination $\mathrm{R}$ Square equals 0.441 , which means that the variables: teamwork, communication, training and development, reward and appreciation explain $44.1 \%$ of the change in the dependent variable, organizational commitment.

The third objective: measuring the impact of job commitment on sustainable development.

The third main hypothesis: There is a significant relationship between job commitment and sustainable development

The first sub-hypothesis: There is a significant relationship between job commitment and economic sustainability

By looking at testing the correlation coefficient between job commitment and economic sustainability. It was found that there is a positive correlation with statistical significance between job commitment and economic sustainability, as the value of the correlation coefficient is 0.442 , with a significance level less than 0.05 .

As for the regression test for job commitment and economic sustainability, the researcher found that there is a positive significant effect on job commitment and economic sustainability as the significance level value is less than 0.05 and the regression coefficient value is 0.385 . Moreover, its $\mathrm{R}$ Square value is 0.196 , which means that $19.6 \%$ of economic sustainability can be explained by regulatory commitment.

Based on the previous results, it can be seen that the first sub-hypothesis of the third hypothesis "there is a statistically significant relationship between job commitment and economic sustainability" is fully acceptable.

The second sub-hypothesis: There is a significant relationship between job commitment and environmental sustainability

An update on the model for testing the correlation coefficient between job 
commitment and environmental sustainability. It was found that there is a positive correlation with statistical significance between job commitment and environmental sustainability, as the value of the correlation coefficient is 0.308 , with a significance level less than 0.05 .

As for the regression model for job commitment and environmental sustainability, the researcher found that there is a positive significant effect for job commitment and environmental sustainability as the significance level value is less than 0.05 and the regression coefficient value is 0.264 . Moreover, its $\mathrm{R}$ Square value is 0.095 , which means that $9.5 \%$ of environmental sustainability can be explained by regulatory commitment.

Based on the previous results, it can be seen that the second sub-hypothesis of the third hypothesis "there is a statistically significant relationship between job commitment and environmental sustainability" is fully acceptable.

The third sub-hypothesis: There is a significant relationship between job commitment and social sustainability

By testing the correlation coefficient between job commitment and social sustainability. It was found that there is a positive correlation with statistical significance between job commitment and social sustainability, as the value of the correlation coefficient is 0.297 , with a significance level less than 0.05 .

Complementing the test of the regression model for job commitment and social sustainability, the researcher found that there is a positive significant effect on job commitment and social sustainability as the significance level value is less than 0.05 and the regression coefficient value is 0.244 . Moreover, its R Square value is 0.088 , which means that $8.8 \%$ of social sustainability can be explained by organizational commitment.

Based on the previous results, it can be seen that the third sub-hypothesis of the third hypothesis "There is a statistically significant relationship between job commitment and social sustainability" is fully acceptable. Based on these results, the third hypothesis "there is a statistically significant relationship between job commitment and sustainable development" is fully acceptable. Therefore, organizational commitment can play the mediating role between organizational culture and sustainable development.

With a view to the structural equation model for organizational commitment to sustainable development, represented in: economic sustainability, environmental sustainability, and social sustainability. The researcher found that there is a positive significant effect between organizational commitment and economic sustainability, as the estimate value is 0.282 , and the significance level value is less than 0.05. Moreover, the value of the coefficient of determination $\mathrm{R}$ Square equals 0.202 , which means that the regulatory commitment explains $20.2 \%$ of the change in the dependent variable, economic sustainability. In addition, the researcher found that there is a positive significant effect between organizational commitment and social sustainability, as the value of the estimate is 0.207 , and the value of the significance level is less than 0.05 . In addition, the value of the 
coefficient of determination, $\mathrm{R}$ Square, is equal to 0.087 , which means that the organizational commitment explains the $8.7 \%$ of the change in the dependent variable, social sustainability. In addition, the researcher found that there is a positive significant effect between organizational commitment and environmental sustainability, as the value of the estimate is 0.245 , and the significance level value is less than 0.05 . In addition, the value of the coefficient of determination R Square equals 0.144 , which means that the regulatory commitment explains $14.4 \%$ of the change in the dependent variable, environmental sustainability.

The fourth main hypothesis: There is a significant role in the relationship between organizational culture and sustainable development

Looking at the multiple regression model of organizational culture on economic sustainability. It has been found that there is a significant impact of organizational culture on economic sustainability. In addition, the results of the multiple regression model test of organizational culture illustrate organizational commitment. It has been found that there is a significant impact of organizational culture on organizational commitment.

It can also be seen that there is a significant effect of organizational commitment on economic sustainability, as its significance level value is less than 0.05. Therefore, organizational commitment fully mediates the relationship between teamwork and economic sustainability, while partly mediating the relationship between communication, training and development, reward and appreciation, and economic sustainability.

Looking at the results of analyzing the role of organizational commitment mediation between organizational culture and environmental sustainability. It has been shown that there is no significant effect of organizational commitment on environmental sustainability as its significance level value is greater than 0.05 , and the results of analyzing the role of organizational commitment mediation between organizational culture and social sustainability have been clarified. It was found that there is no significant effect of organizational commitment on social sustainability, as its significance level value is greater than 0.05 . The results of analyzing the role of the mediation of organizational commitment between organizational culture and sustainable development also showed. The researcher found that there is a significant effect of organizational commitment on economic sustainability when the value of the significance level is less than 0.05 , which means that organizational commitment can play the role of a mediator between organizational culture and economic sustainability, while there is no significant effect of organizational commitment on both sustainability. Social, and environmental sustainability as the significance level value is greater than 0.05 . It can be seen that organizational commitment completely mediates the relationship between teamwork, training and development, and economic sustainability, while partly mediating the relationship between communication, reward and appreciation and economic sustainability. 


\subsection{Recommendations}

This research has some recommendations according to what was found in the results. Some are suggested for current research while others are included for future research. With regard to the recommendations of current research, reaching and achieving sustainable development, it is recommended to enhance the use and application of organizational culture and job commitment to be able to achieve sustainable development and increase social, economic and environmental development. With regard to recommendations for future work, it is recommended to increase the sample size for future and future research.

\subsection{Limitations and Suggestions for Future Research}

It is known that in most experimental studies there are some limitations to this research, which may prevent generalization of the results. It has been suggested to expand the sample of companies that apply organizational culture policy in future studies. As this research, analysis was applied to the employees of Citadel Capital, as it applies the organizational culture policy. It is necessary to increase and expand the sample size to obtain more reliable and general results. Perhaps observing the influence of organizational culture on sustainable development in different countries could have yielded results that are more significant.

Further studies can be done in both developed and developing countries and then the results obtained can be compared. In addition, time was a limitation for the current research study and inclusion of a large sample may lead to results that are more reliable. Besides, the study did not include other factors that could affect the relationship between organizational culture and sustainable development. Moreover, future research may be considered to study a larger time interval as our research focuses only on the academic year 2019/2020. Hence, there is an urgent need to consider a longer period of future research.

\section{Conflicts of Interest}

The authors declare no conflicts of interest regarding the publication of this paper.

\section{References}

[1] Svensson, G. and Wagner, B. (2015) Implementing and Managing Economic, Social and Environmental Efforts of Business Sustainability. Management of Environmental Quality: An International Journal, 26, 195-200.

https://doi.org/10.1108/MEQ-09-2013-0099

[2] Cohen, M.J. (2001) The Emergent Environmental Policy Discourse on Sustainable Consumption. In: Exploring Sustainable Consumption, Pergamon, 21-37. https://doi.org/10.1016/B978-008043920-4/50005-7

[3] Cameron, K. (2008) A Process for Changing Organization Culture. Handbook of Organization Development, 14, 2-18.

[4] Aier, S. (2014) The Role of Organizational Culture for Grounding, Management, Guidance and Effectiveness of Enterprise Architecture Principles. Information Sys- 
tems and E-Business Management, 12, 43-70. https://doi.org/10.1007/s10257-012-0206-8

[5] Duffy, R.D. and Richard, G.V. (2006) Physician Job Satisfaction across Six Major Specialties. Journal of Vocational Behavior, 68, 548-559.

https://doi.org/10.1016/j.jvb.2005.12.001

[6] Hegney, D., Plank, A. and Parker, V. (2006) Extrinsic and Intrinsic Work Values: Their Impact on Job Satisfaction in Nursing. Journal of Nursing Management, 14, 271-281. https://doi.org/10.1111/j.1365-2934.2006.00618.x

[7] Chileshe, N. and Haupt, T.C. (2007) Age Influences on the Job Satisfaction of Construction Workers: Evidence from South Africa.

[8] Baumgartner, R.J. and Rauter, R. (2017) Strategic Perspectives of Corporate Sustainability Management to Develop a Sustainable Organization. Journal of Cleaner Production, 140, 81-92. https://doi.org/10.1016/j.jclepro.2016.04.146

[9] Linnenluecke, M.K. and Griffiths, A. (2010) Corporate Sustainability and Organizational Culture. Journal of World Business, 45, 357-366.

https://doi.org/10.1016/j.jwb.2009.08.006

[10] ALshbiel, S.O. and Al-Awawdeh, W.M. (2011) Internal Social Responsibility and Its Impact on Job Commitment: Empirical Study on Jordanian Cement Manufacturing Co. International Journal of Business and Management, 6, 94. https://doi.org/10.5539/ijbm.v6n12p94

[11] Nongo, E.S. and Ikyanyon, D.N. (2012) The Influence of Corporate Culture on Employee Commitment to the Organization. International Journal of Business and Management, 7, 21-28. https://doi.org/10.5539/ijbm.v7n22p21

[12] Khan, A.S. and Jan, F. (2015) The Study of Organization Commitment and Job Satisfaction among Hospital Nurses. A Survey of District Hospitals of Dera Ismail Khan. Global Journal of Management and Business Research, 15, 17-20.

[13] Neuman, D. (2014) Qualitative Research in Educational Communications and Technology: A Brief Introduction to Principles and Procedures. Journal of Computing in Higher Education, 26, 69-86. https://doi.org/10.1007/s12528-014-9078-x 